\title{
VERTICAL RESTRAINTS AND PRODUCERS' COMPETITION
}

\author{
Patrick REY \\ INSEE, 75014 Paris, France \\ Joseph STIGLITZ \\ University of Princeton, Princeton, NJ 08544, USA
}

\section{Introduction}

Vertical relationships between producers and retailers or wholesalers often involve more or less complex contracting arrangements, broadly named vertical restraints. These arrangements can simply consist in non-linear tariffs, such as franchise fees, quantity forcing or pricing requirements (quotas, Resale Price Maintenance), but they may also include the assignment of exclusive territories or exclusive dealing, tie ins, etc. ${ }^{1}$ This paper is concerned with investigating the rationale for these restrictions and showing that there are important circumstances under which these restrictions have a significant anti-competitive effect, at the upper level as well as at the lower one.

The legal status of these restraints is not very clear, as it differs among countries and changes over times. ${ }^{2}$ From the economic point of view, two main streams of ideas have emerged from the beginning: on one side, some produce the argument that, as markets are competitive and as these arrangements can be adopted only if joint profits are increased, there must necessarily be a gain in efficiency; on the other side, some emphasize the anticompetitive effects of these restraints at the lower (retailers' or wholesalers') level.

Recently, some efforts have been done in order to formalize the efficiency argument [see for example Mathewson and Winter (1983), (1984)]. The vertical relationship is viewed as a principal-agent(s) one, and the emphasis

\footnotetext{
${ }^{1}$ See Blair and Kaserman (1983) and Caves (1984) for a general presentation of vertical restraints, as well as a comprehensive discussion of their economic incidence.

${ }^{2}$ For instance, RPM is generally considered as illegal; however, some States in the U.S. had for a while adopted 'fair trade' laws, which partially authorized RPM. Thus, even looking only to the case of the U.S., RPM, which was originally viewed as per se violation of the Sherman Act, has then been accepted in some States, till 1975; it is now again illegal in all States. In the same way, assigning exclusive territories, after having been considered as per se illegal, is now subject to a rule of reason.
} 
is placed on control problems: a monopolistic producer deals with a set of more or less competitive retailers, whose actions (retail prices, selling efforts, etc.) affect the total profits; the problem for the producer is thus to design a contract in order to achieve the integrated solution, i.e., to make the retailers choose the right actions and to recover back the generated profits. The main conclusion in this framework is that vertical restraints are always privately desirable, as they allow a better control of the retailers. ${ }^{3}$ Moreover, as they help in correcting externalities associated with linear pricing rules, such as the double marginalization problem [Spengler (1950)] or the free-rider problem [Telser (1960)], these vertical restraints are usually thought of as increasing social welfare.

This apologetical view has already been shaded by recent works, which emphasize for instance the divergence between the monopolist's and the consumers' valuations for distributors' services [see Scherer (1983), Comanor (1985) and Caillaud and Rey (1987)] or the role of distributors' private information in uncertain markets [see Rey and Tirole (1986b)]. The general framework is however the same, and in particular inter-brand competition (i.e., competition among producers) is neglected.

We will argue here that producers' competition is in fact a crucial element for the analysis of vertical arrangements. As we will show, when several producers are imperfectly competing at the upper level, then vertical restraints may serve to facilitate collusion. The contractual arrangement may indeed be efficient, in the sense that joint profits are higher, but the gains to the producers and distributors are at the expense of consumers. Vertical restraints may not thus be socially desirable.

We aim to emphasize the interaction between the internal (producer/ retailer) contract designing and the external competitive situation at the upper level. The natural framework is provided by the multiprincipal-multiagents approach which, developed by Fershtman and Judd $(1984,1986)$, has recently been analysed by Bernheim and Whinston (1986), in the case of common agency, and by Katz (1987), in the case of rivalrous agencies. This approach stresses in particular the role of internal principal/agents contracts as a commitment for sustaining collusion among principals; it also emphasizes the importance of the definition of admissible contracts and the role of each agent's information. This approach has already yielded new insights in the analysis of imperfect competition [see respectively Bernheim and Whinston (1985) and Bonanno and Vickers (1987) for applications in contexts of common and rivalrous agencies). As we will see, it also constitutes a useful tool for the analysis of the rationale and the incidence of vertical restraints.

\footnotetext{
${ }^{3}$ For an introduction to this literature on vertical control, see Rey and Tirole (1986a). Indeed, one of the objectives of this literature is to define the 'minimal sets of sulficient tools', which lead to a perfect control of the distributors by the producer. \{Exclusive territories plus franchise fees\} generally constitutes an example of such a minimal set: it amounts in fact to 'sell the firm' (or, more exactly, the production technologyl to distributors.
} 


\section{Exclusive territories as a device to reduce competition}

We consider here a simple model, borrowed from Rey and Stiglitz (1985), which shows how exclusive territories, which obviously reduce competition at the lower level, may actually be a way of reducing competition at the upper level as well. The basic idea is that when retailers enjoy some kind of monopolistic power, they may put higher mark-ups in the retail price: this price distortion, in turn, induces some change on the cross sensitivity of this demand towards the prices of the manufacturer's competitors. The manufacturers may therefore perceive a less elastic demand than when they directly compete with each other or address to competitive retailers. This effect in turn may induce both producers to assign exclusive territories to their retailers.

Let us describe this model. There are two manufacturers, each producing a simple good with a constant marginal cost $c_{i}$ and distributing it via retailers who have no retail costs. The two products are imperfect substitutes. The final demand for good $i$, associated to retail prices $q_{1}$ and $q_{2}$, is given by $D_{i}\left(q_{1} q_{2}\right)$. For simplicity, we assume symmetry: $c_{1}=c_{2}$ and $\forall x, y \in \mathbb{R}_{+}, D_{1}(x, y)=$ $D_{2}(y, x)$. Consumers have no search cost and thus buy from the lowest possible price for each product. Lastly, we will suppose in the following that all profit functions are concave admit a unique - and interior - maximum. and we will thus focus on first-order conditions.

We can define two useful benchmarks, corresponding respectively to perfect collusion and direct competition between producers:

- the collusive outcome is defined by the maximization of the aggregate profits $\left(q_{1}-c\right) D_{1}\left(q_{1}, q_{2}\right)+\left(q_{2}-c\right) D_{2}\left(q_{1}, q_{2}\right)$, and leads to the monopolistic price $q^{m}$

$$
\left(q^{m}-c\right) / q^{m}=1 /\left(\varepsilon_{1}\left(q^{m}, q^{m}\right)+\varepsilon_{2}\left(q^{m}, q^{m}\right)\right),
$$

where $\varepsilon_{1}$ and $\varepsilon_{2}$ respectively denote the direct and cross price elasticities of the final demands $\left(\varepsilon_{i}=-\partial \log D_{1} / \partial \log q_{i}\right)$. The monopolistic mark-up is thus the higher, the lower is the sensitivity of the demand for a product with respect to its own price and the higher is the sensitivity of this demand to the price of the other product. ${ }^{4}$

- the outcome associated to direct competition corresponds to the (Nash) equilibrium of the game defined by producer is strategy $q_{i}$ and payoff $\left(q_{1}-c\right) D_{i}\left(q_{1}, q_{2}\right)$. The 'competitive' price $q^{f}$ is characterized by (under standard assumptions on payoffs functions)

$$
\left(q^{c}-c\right) / q^{c}=1 / \varepsilon_{1}\left(q^{c}, q^{c}\right)
$$

Of course the 'competitive' profits are lower. When the two products are

"As the two goods are substitutes, one has $\varepsilon_{2} \leqq 0$. 
substitutes, retail prices also are lower; the basic idea is that each producer, when he chooses his own price, does not take into account the fact that his rival's demand gains from an increase in his own price. Note that indeed, it would be in the interest of the producers to convince each other that they would follow up any price increase.

Let us now make precise the competitive framework. It is supposed that producers observe the quantity bought by the retailers and possibly whether or not the retailers distribute their products; they do not observe neither the quantities sold by the retailers nor their profits or the prices they charge. On the contrary, retailers have perfect information and observe the contracts signed by each producer; in particular, they can do arbitrage if a producer tries to discriminate between them. Finally, producers may assign exclusive territories to their retailers (in which case these territories are supposed to be symmetric and thus representative of the total market). ${ }^{5}$ Given these informational assumptions, the admissible contracts between a producer and his retailers can only include, besides the assignment of exclusive territories, wholesale tariffs based on the quantity bought by the retailers. The possibility of arbitrage from the retailers rules out non constant marginal prices; producers may however impose franchise fees on the retailers if they effectively observe who sell their products. We will consider both situations.

We formalize the competition framework as a two-stage game: in the first stage, given some vertical contracting arrangement, producers simultaneously choose their wholesale prices, $p_{1}$ and $p_{2}$ (and eventually the franchise fees); then in the second stage, retailers observe all wholesale tariffs and simultaneously choose their retail prices. We will consider in the following the (subgame) perfect equilibria of this two-stage game, corresponding to two initial situations: in the first one, retailers are pure price competitors whereas in the second one, exclusive territories have been assigned to the retailers. (i) In absence of vertical arrangement, pure (intra-brand) price competition leads the retailers to charge zero mark-ups in the second stage, and thus the retail prices are finally equal to the wholesale prices chosen in the first stage: $q_{i}=p_{i}$ (this in turn implies that franchise fees, even if they are available, must be equal to zero). The situation is therefore formally identical to the situation of 'direct' competition between producers, that we already characterized. At the end of this subgame, the wholesale and retail prices are equal to the 'competitive' price $q^{c}$, retail profits are zero and producers get the 'competitive' profits.

\footnotetext{
${ }^{5}$ The following assumptions are more precisely presented and discussed in Rey and Stiglitz (1985). The two main assumptions are the asymmetry in information between retailers and producers about retail prices and sales, and the fact that all contracts are common knowledge. The first assumption may be justified in several ways, including moral hazard aspects on the retail side [see Rey and Tirole (1986b)]. The assumption that the retailers observe all producers' contracts allows producers, as we will see, to use these contracts in order to achieve better profits: they are therefore strongly interested in making them common knowledge.
} 
(ii) Let us now suppose that producers have assigned exclusive territories to their retailers. These arrangements eliminate intra-brand competition and thus each retailer enjoys a monopolistic power over some fixed fraction of the final demand for his product. Given the producers' prices $p_{1}$ and $p_{2}$, at the second stage some retail price equilibrium will emerge, described by $\left(q_{1}^{\prime}\left(p_{1} p_{2}\right), q_{2}^{\prime}\left(p_{1} p_{2}\right)\right)$ : each retail price is a function of the two producers' prices; note that franchise fees, which should be viewed as fixed costs, can alter the retailers' decisions about distributing or not a product, but do not change the price response functions. For simplicity, we will again assume symmetry: $\forall x, y \in \mathbb{R}_{+}, q_{1}^{\prime}(x, y)=q_{2}^{\prime}(y, x)$.

(a) Suppose first that franchise fees are not available. At the first stage producer $i$ chooses a price $p_{i}$ to maximize

$$
\pi_{i}=\left(p_{i}-c\right) D_{i}\left(q_{1}^{\prime}\left(p_{1}, p_{2}\right), q_{2}^{\prime}\left(p_{1}, p_{2}\right)\right)
$$

which leads to wholesale and retail prices which satisfy $p_{1}=p_{2}=p^{e}, q_{1}=q_{2}=$ $q^{e}=q_{i}^{\prime}\left(p^{e}, p^{e}\right)$, and

$$
\left(p^{e}-c\right) / p^{e}=1 /\left[\varepsilon_{1}\left(q^{e}, q^{e}\right) \rho_{1}\left(p^{e}, p^{e}\right)+\varepsilon_{2}\left(q^{e}, q^{e}\right) \rho_{2}\left(p^{e}, p^{e}\right)\right],
$$

where $\rho_{1}$ and $\rho_{2}$ respectively denote the elasticities of a given retailer's price to his producer's (for $\rho_{1}$ ) and the rival's (for $\left.\rho_{2}\right)$ wholesale prices $\left(\rho_{i}=\partial \log q_{1}^{\text {r) }}\right.$ $\left.\partial \log p_{i}\right)$.

(b) Suppose now that producers can require franchise fees. Anticipating the retail price equilibrium (which, as already noticed, is not modified when introducing franchise fees), the producer can recover via the franchise fees the associated retail profits. Thus producer i's profits are given by

$$
\pi_{i}=\left(q_{i}^{r}\left(p_{1}, p_{2}\right)-c\right) D_{i}\left(q_{1}^{r}\left(p_{1}, p_{2}\right), q_{2}^{r}\left(p_{1}, p_{2}\right)\right) \text {. }
$$

The equilibrium condition becomes

$$
\left(q^{f}-c\right) / q^{f}=1 /\left(\varepsilon_{1}\left(q^{f}, q^{f}\right)+\varepsilon_{2}\left(q^{f}, q^{f}\right) \rho_{2}\left(q^{f}, q^{f}\right) / \rho_{1}\left(q^{f}, q^{f}\right)\right) .
$$

Let us briefly comment on this analysis. If, as one might normally expect, competitive pressures result in $\rho_{1}$ being positive but less than one, and $\rho_{2}$ being positive but less than $\rho_{1}{ }^{6}$ then one obtains

\footnotetext{
${ }^{6}$ Retailers that find that their wholesale prices have increased while their competitors have not do not simply pass on the cost increase with the usual mark-up, but rather absorb some of the cost increase themselves (i.e., $0 \leqq \rho_{1} \leqq 1$ ). This in turn induces the competitors to increase their own retail prices $\left(\rho_{2} \geqq 0\right)$; it seems however reasonable to suppose that the direct effect, measured by $\rho_{1}$, is higher than the indirect one: $\rho_{2} \leqq \rho_{1}$.
} 


$$
q^{e} \geqq p^{e} \geqq p^{c}=q^{c} \quad \text { and } \quad q^{m} \geqq q^{f} \geqq q^{c}
$$

Thus, when exclusive territories are assigned, and whether or not franchise fees are required, the equilibrium retail prices are higher.

In the case where franchise fees are not allowed, wholesale prices also are higher when exclusive territories are assigned. This only comes from a change in the elasticity of the perceived demand; this change results from two effects: first, the reduction of demand is altered by the fact that the retail price of a product only partially responds to the corresponding wholesale price; secondly, the loss of sales is also decreased because the rival's retailers, who then face higher retail prices, find it optimal to increase their own prices. This change of the sensitivity of the demand leads to higher wholesale price response functions and, thus, to higher wholesale price at the equilibrium. If double marginalization problems are not too important, then producer's profits also are higher when exclusive territories are assigned to retailers.

In the case where franchise fees are allowed, then the above analysis shows that under reasonable assumptions, producers' profits are higher when exclusive territories are assigned. This does not only come from a decrease of the elasticity of the perceived demand (note in particular that wholesale prices need not be higher), but also from the fact that, by assigning exclusive territories to their retailers, producers generate higher retail prices.?

\section{Comments}

In the model just analysed, the producers are presumably better off when exclusive territories are assigned to the distributors. It does not a priori imply that producers will indeed assign exclusive territories to their retailers (unless they can cooperatively agree to do so). A possible way for analysing the producers' choices of vertical arrangements consists in introducing a new stage at the beginning of the game, where each producer chooses between competition and exclusive territories for his retailers. Rey and Stiglitz (1985) provides an example where assigning exclusive territories and requiring franchise fees is actually a dominant strategy for each producer, although the corresponding outcome is Pareto dominated by the outcome associated to the situation where both producers commit themselves to assign exclusive territories and to require no franchise fees (there is thus a standard 'prisoners' dilemma'). This example highlights the potential role of vertical restraints for decreasing producers' competition and also emphasizes the

\footnotetext{
${ }^{7}$ Similar effects are present in the context analysed by Bonanno and Vickers (1987). Two situations are there compared: the first one corresponds to what we called 'direct competition' between producers; in the second one, each producer delegates to a single agent the distribution of his good. Formally, the first situation is similar to the situation where each product is distributed via perfectly competitive retailers, while the second situation (delegation) corresponds to exclusive territories in our framework.
} 
divergence between collective and individual rationalities: two phenomena which were ignored in most of the previous analyses of vertical restraints. ${ }^{8}$ Indeed in this analysis, retailers can be considered as 'black boxes' or 'response machines'; by modifying the vertical arrangements proposed to his retailers, a producer simply commits himself to respond in a given way to any change of his rivals' attitudes. Of course if all possible 'response machines' were available, complete collusion would then be achievable [see Katz (1987)]; the question therefore is to define the admissible 'black boxes'. In this respect, vertical restraints can be viewed as a natural tool for constructing more efficient response machines, i.e., response machines which enable the producers to decrease competition at their level. For instance, in the previous model, producers could modify the design of territories in order to decrease as much as possible the elasticity of the perceived demand; or they could give the right to sell their products to the same retailers (common agency), or distribute their product via wholesalers, who in turn could assign exclusive territories to retailers, etc. In other contexts, depending on observability and enforceability conditions, different vertical restraints might also be introduced to extend the set of available 'response machines'.

This analysis sheds new lights on the economic effect of the use of vertical restraints on markets performance and social welfare. Till now, two extreme situations were mainly considered: the first one refers to perfectly competitive markets, where only efficiency arguments can explain the use of these restraints; the second situation corresponds to the case of a monopolistic producer and, although private and social interests may conflict, at least from the private point of view efficiency arguments may still, to some extent, be relevant. But if one considers a situation where there is imperfect competition at the upper level (which is generally true in most famous cases involving the use of vertical restraints), then a new motivation appears: vertical restraints may be uscd only to decrease competition betwecn producers; this has usually a negative impact on the social welfare, the gain in additional profits being overwhelmed by the loss of consumers' surplus. Of course the above analysis is very partial; it however suggests a new approach for the economic theory of vertical restraints.

\footnotetext{
${ }^{8}$ Telser (1960) and Posner (1977) suggested that RPM could help producers in sustaining collusion by reducing the interest of wholesale price cuts. It has also been suggested that exclusivity requirements (such as exclusive dealing) can serve to deter entry, as they compel the potential entrants to set up their own distribution networks.
}

\section{References}

Bernheim. B.D. and M.D. Whinston, 1985, Common marketing agency as a device for facilitating collusion, Rand Journal of Economics 16, 269-281.

Bernheım. B.D. and M.D. Whinston, 1986, Common agency, Econometrica 54, no. 4, 923-942.

Blair, R. and D. Kaserman, 1983, Law and economics of vertical integration and control (Academic Press, New York). 
Bonanno, G. and J. Vickers, 1987. Vertical separation, Nuffield College discussion paper, forthcoming in Journal of Industrial Economics.

Caillaud. B. and P. Rey, 1987, A note on vertical restraints with provision of distribution services, INSEE discussion paper no. 8702.

Caves, R., 1894, Vertical restraints in manufacturer-distributor relations: Incidence and economic effects, Mimeo. (Harvard University).

Comanor, W.S., 1985, Vertical price fixing and market restrictions and the new antitrust policy, Harvard Law Review 98, no. 5, 983-1002.

Fershtman, C. and K.L. Judd, 1984. Incentives equilibrium in oligopoly, CSMEMS working paper no. 642 (Northwestern University).

Fershtman, C. and K.L. Judd, 1986, Strategic incentive manipulation in rivalrous agency, Mimeo.

Katz, M. 1987, Game-playing agents: Contracts as precommitments, Princeton University discussion paper, Feb.

Mathewson, G.F. and R. Winter, 1983, The economics of vertical restraints in distribution, in: I.E.A. Conference Volume, New developments in the analysis of market structure (Macmillan, New York), forthcoming.

Mathewson, G.F. and R. Winter, 1984, An economic theory of vertical restraints, Rand Journal of Economics 15, Spring, 27-38.

Posner, R., 1977, The rule of reason and the economic approach: Reflections on the Sylvania decision, University of Chicago Law Review 45, Fall, 1-20.

Rey, P. and J. Stiglitz, 1985, The role of exclusive territories on producers' competition, Mimeo., revised version July 1987.

Rey, P. and J. Tirole, 1986a, Vertical restraints from a principal-agent viewpoint, in: L. Pellegrini and S.K. Reddy, eds., Marketing channels (Lexington Books, Lexington, MA) 330.

Rey, P. and J. Tirole, 1986b, The logic of vertical restraints, American Economic Review 76, no. $5,921-939$.

Scherer, F.M., 1983, The econcmics of vertical restraints, Antitrust Law Journal 52, no. 3, 687707.

Spengler, J., 1950, Vertical integration and anti-trust policy, Journal of Political Economy 58, Aug., 347-352.

Telser, L., 1960, Why should manufacturers want fair trade?, Journal of Law and Economics 3, Oct., 86-105. 